\title{
Resilience of Parents with a Child with Autism Spectrum Disorders and Factors for Its Potential Enhancement: Family Income and Educational Level
}

\author{
Paschalis Kavaliotis $^{1}$ \\ ${ }^{1}$ Department of Special Education and Psychology, Faculty of Primary Education, National and Kapodistrian \\ University of Athens, Greece \\ Correspondence: Paschalis Kavaliotis, Department of Special Education and Psychology, Faculty of Primary \\ Education, National and Kapodistrian University of Athens, Greece. E-mail: apk1@otenet.gr
}

Received: February 1, 2017

Accepted: February 10, 2017 Online Published: February 15, 2017

doi:10.5539/jedp.v7n1p188

URL: http://doi.org/10.5539/jedp.v7n1p188

\begin{abstract}
Autism is linked to bodily and psychological challenges for the parents who raise autistic children, it creates increased stress levels and reduced resilience because of these factors. However, many parents face the additional problem of the weakness to cope with the expenses of each therapeutic intervention, whereas often they are not adequately educated so as to be able to manage properly the information about the treatment of autism and maybe also its intake as a compulsory condition for the family environment. The writer explored the effect of family income and the parents' educational level on the reduction of resilience through a quantitative research based on a population sample that consisted of the parents of 312 autistic children in Greece, all of them couples, namely 624 men and women, divided in equal numbers. The important impact of the annual family income on the shaping of the levels of the characteristics under study is confirmed, as the result that was drawn is that the level of financial strength is positively connected to the social support the parents receive and the resilience they develop. Likewise, the level of education is linked to social support. The social support increases when the educational level is higher, on the contrary, the opposite goes for the levels of the total stress, parental distress, parent-child dysfunctional interaction, difficulty of child, which the lower educational level increases.
\end{abstract}

Keywords: resilience, autism, autistic child, family income, parents' educational level, social support

\section{Introduction}

The researches in the latest years (2013-2016) have not allowed the composition of a widely theoretical framework about the effect of the family income and the parents' educational level, as factors of possibly reinforcing the resilience during the autistic child's upbringing. And even if these researches contain some references to the family income, the references to the educational level are scarce and rather indirect. Nonetheless, certain useful observations could be the following:

An important factor causing stress is the financial pressure in coping with the autism problems, since the intervention strategies are not only time-consuming, but also expensive. Both the proper food for the child may be expensive and the necessary medication, too, whereas the health insurance is insufficient to cover all the needs of raising an autistic child (Bashir et al., 2014). Obviously, the economic efficiency is not a determining factor itself, as the parenting stress intervenes negatively, which according to Batool and Khurshid (2015) stems from the unpleasant situation during where the balance between the parents' views on the demands of the upbringing of their autistic children and their views on the possibility to utilize their resources effectively for addressing the problem, is disrupted. Bhagat, Simbak and Haque (2015) characterize autism as a serious, persistent and dynamic disease the consequences of which are made worse by the way the parents behave to their children, influenced negatively also by the negative problems they face. The therapeutic interventions will have to take into account the financial matters very seriously.

The data on the educational level, as mentioned already, is even more indirect, however, the results that are drawn are not insignificant. Samadi and McConkey (2014) believe that it affects the health of the parent cares but they also support the usefulness of broader knowledge on autism which overrides the cultural differentiations 
of the autistic children's care. Of course, good information and increased knowledge do not necessarily mean that the parents' educational level is higher, but when the information comes from books and computers, it may correspond to a more educated family. As it will be shown also by the views of Ammari, Ringel Morris and Yardi Schoenebeck (2016) presented in the section "DISCUSSION", maybe the choice of the information sources depends on the parents' educational level, who will have to be in a position to distinguish the correct piece of information from the incorrect one. In the section "DISCUSSION", other surveys are mentioned too, in which the sensitive field of information derived from the internet and the bibliography, such the survey by Selimoglu et al. (2013).

\section{Method}

\subsection{Purpose}

This article is part of a wider research that aimed in exploring the way in which the family resilience of parents with a child with autism spectrum disorders interacts with the social context among which the family is placed, as well as with the stress the parents experience during the upbringing of a child with autism spectrum disorders. It is important to investigate how the resilience is affected when the social support that the family receives is low and the true stress high, with variables, apart from the level of social support that the parents receive and the stress they suffer from, certain demographic characteristics of the parents and of the child, too, such as age, sex and the diagnosis of the syndrome the child suffers from. In this article, the results of the investigation of the relation between the family resilience of the parents and the family income, as well as between the resilience and the educational level, are shown. It was assumed that a better income would lead to an easier addressing of the autistic child's needs, while a higher educational level would cause more favorable conditions of understanding the situation on the part of the parents and of its addressing.

\subsection{Participants}

Table 1. Demographic and other characteristics of the participants in the survey

\begin{tabular}{|c|c|c|}
\hline & $\mathbf{n}$ & $\%$ \\
\hline \multicolumn{3}{|l|}{$\operatorname{Sex}$} \\
\hline Men & 312 & 50,0 \\
\hline Women & 312 & 50,0 \\
\hline \multicolumn{3}{|l|}{ Nationality } \\
\hline Greek & 609 & 97,6 \\
\hline Other & 15 & 2,4 \\
\hline \multicolumn{3}{|l|}{ Religion } \\
\hline Christians & 586 & 93,9 \\
\hline Muslims & 38 & 6,1 \\
\hline \multicolumn{3}{|l|}{ Prefecture of } \\
\hline Kavala & 52 & 8,3 \\
\hline Rodopi & 80 & 12,8 \\
\hline Xanthi & 72 & 11,5 \\
\hline Cyclades & 74 & 11,9 \\
\hline Serres & 96 & 15,4 \\
\hline Drama & 120 & 19,2 \\
\hline Evros & 130 & 20,8 \\
\hline \multicolumn{3}{|l|}{ Education } \\
\hline Primary Education & 171 & 27,4 \\
\hline Secondary School Graduates & 80 & 12,8 \\
\hline Lyceum Graduates & 168 & 26,9 \\
\hline HEI /TEI Graduates & 205 & 32,9 \\
\hline Studies in Psychology or in Special Education & 0 & 0,0 \\
\hline
\end{tabular}




\begin{tabular}{lcc}
\hline Annual Family Income & & \\
Below $15.000 €$ & 266 & 42,6 \\
$15.000 €-20.000 €$ & 272 & 43,6 \\
Over $20.000 €$ & 86 & 13,8 \\
Family Status & & \\
Single & 0 & 0,0 \\
Married & 624 & 100,0 \\
Widower/ Widow & 0 & 0,0 \\
Divorced & 0 & 0,0 \\
Family Relation to the Child & & 50,0 \\
Biological Father & 312 & 50,0 \\
Biological Mother & 312 & 0,0 \\
Step-father & 0 & 0,0 \\
Step-mother & 0 & \\
\hline
\end{tabular}

As shown in Table 1, 624 parents of 312 children with autism spectrum disorders participated in the survey. The sample is uniformly distributed as to the parents' sex with $50.0 \%$ men and the same percentage of women. $97,6 \%$ of the sample, namely 609 parents, are Greeks, whereas $2,4 \%$, namely 15 participants, are of a different nationality. 586 of the participants are Christians, $93,9 \%$ of the sample, whereas the remaining $6,1 \%$, that is to say, 38 parents, are Muslims. As far as their place of residence in the Greek territory is concerned, 52 parents $(8,3 \%$ of the total number) reside in the prefecture of Kavala, 80 parents $(12 \%$ of the total number) reside in the prefecture of Rodopi, 72 participants (11,5\% of the sample) in the Xanthi prefecture, 74 parents $(11,9 \%$ of the sample) in the prefecture of Cyclades, 96 parents $(15,4 \%$ of the total number) in the prefecture of Serres, 120 parents $(19,2 \%$ of the total) in the prefecture of Drama and 130 parents $(20,8 \%$ of the sample) in the prefecture of Evros.

The total number of the respondents $(100,0 \%$ of the sample) are married and they are the biological parents of the child with autism spectrum disorders, 312 (50,0\% of the sample) are the biological mothers and $312(50,0 \%$ of the sample) the biological fathers.

The highest level of education for $27,4 \%$ of the participants (171 parents) is that of the primary education, $12,8 \%$ of the participants ( 80 parents) have received a low secondary education (gymnasium), 26,99\% (168 parents) have received a high secondary education (lyceum), whereas the rest of the participants, that is to say, $32,9 \%$ of the sample (205 parents) have received a post-secondary education, as they are graduates of Higher Educational Institutes (HEI) and Technological Educational Institutes (TEI).

Concerning the annual family income, $42,6 \%$ of the sample (266 parents) declared an amount below $15.000 €$, $43,6 \%$ of the total number (272 parents) between $15.000 €$ and $20.000 €$ and the remaining $13,8 \%$ (86 parents), an income over $20.000 €$.

The children's characteristics are summarized in Table 1 in this text.

Table 2. Sex of the children with Autism spectrum disorders and Asperger syndrome

\begin{tabular}{lcc}
\hline & $\mathbf{n}$ & $\mathbf{\%}$ \\
\hline Sex & & \\
Boy & 253 & 81,1 \\
Girl & 59 & 18,9 \\
Diagnosis & & \\
Autism & 282 & 90,4 \\
Asperger & 30 & 9,6 \\
I don't know & 0 & 0 \\
\hline
\end{tabular}


Table 3. Characteristic age values of the children with autism spectrum disorders

\begin{tabular}{lcccc}
\hline & $\begin{array}{c}\text { Mean } \\
\text { Value* }\end{array}$ & $\begin{array}{c}\text { Standard } \\
\text { Deviation }\end{array}$ & Skewness \\
\hline The Age of Children with Autism Spectrum Disorders & & & & 1,45 \\
\hline
\end{tabular}

With regard to the child's sex, $81,1 \%$ of the respondents, namely 506 in number, are boys' parents and the remaining 118 parents $(18,9 \%$ of the sample) are girls' parents. The average age of the 312 children whose parents participated in the research is $M=12,45$ years with standard deviation $S D=5,3$ years. $90,4 \%$ of these children, that is to say, 282 in terms of numbers, have been diagnosed with autism, whereas the remaining 30 children, $9,6 \%$ of the total number, have been diagnosed with Asperger syndrome. The children's characteristics are summarized in Tables 2 and 3 in the present text.

\subsection{Note}

The demographic characteristics of the families with dysfunctional children are factors relating directly to the parents' stress levels (Houser \& Seligman, 1991; Keller \& Honig, 2004). For this reason the questionnaire that was distributed to the participants contained specific fields the completion of which would provide the necessary demographic information on each family, namely on the sex, nationality, religion, education level, annual family income, current family status, family relation to the autistic child, the child's age and sex, as well as his accurate diagnosis.

\subsection{Data Collection}

The supplying and collection of the questionnaires were realized by the writer from July 2015 to February 2016. The search for parents with children with autistic spectrum disorders was conducted based on the catalogues of the Center for Differential Diagnosis, Diagnosis and Support (KE.D.D.Y.) in the prefectures of the Greek territory, where an archive is kept on the children that receive a diagnosis. The parents were approached via mail sent to their residence address, to which the research questionnaire was attached, as well as an accompanying form that informed them in detail of the purpose and the aims of the research process. Special emphasis was put on the importance of confidentiality and anonymity of the information, namely that the data of the child and of the parents themselves would remain anonymous, whereas the information will be used exclusively for the needs and the purpose of the present research.

Though the accompanying form the parents were informed that they had to complete the entire questionnaire and the duration of its completion should not exceed 60 minutes. The participants were urged to contact the researcher on his mobile phone for the provision of instructions and clarifications about the correct completion of the questionnaire. Moreover, the importance of the completion by every parent separately was specifically pointed out to the participants, without there being an exchange of views among the couples, so that the achievement of the research's aims be possible.

The collection of the completed questionnaires was realized with their return to the researcher, by mail, from the families that had consented to an analysis of their answers. The return of the questionnaires to the researcher was defined to take place within 30 days after the date of their dispatching to these families.

\subsection{Data Analysis}

For the investigation of the relations that govern the Social Support, Family Resilience and Parental Stress of parents with children with Autism spectrum disorders, the following three data collection tools were used.

Social Support Index: The degree of the social support of parents who have a child with autism spectrum disorders was measured with the widely spread SSI tool (McCubbin, Patterson, \& Glynn, 1982) which assesses the family social support as a factor in family resilience (Fischer, Corcoran, \& Fischer, 2007). It contained 16 questions the answers to which were given in the 5-point Likert scale ( 0 up to 4$)$. In every questionnaire statement, the respondents can state the measure of their agreement or disagreement by choosing one of the following answers: "I strongly disagree", "I agree", "I am not sure", "I agree" and "I fully agree", which are ranked on a scale of 0 to 4 . In certain answers the scale was reversed so that a common conceptual content could 
be achieved. As to the answers' interpretation for the definition of the Social Support degree, the scores of the individual questions are summed, the highest scores indicating a highest Social Support degree. The span of the SSI scale was from 0 to 6 units. The SSI has a high internal validity index with a $=0,82$. The Social Support scale was used as an independent variable.

Family Resilience Assessment Scale: The FRAS scale of Tucker Sixbey (2005) was used to measure Family Resilience, based on the theoretical standard of Walsh (2006) on family resilience. It contained 66 closed-type questions which, as in the SSI case, they were answered in the Likert scale, but in a 4-point one, with values varying from 1 to 4, corresponding to the choices: "I strongly disagree", "I disagree", "I agree" and "I fully agree". The scale was reversed in four of these questions, and again for the acquisition of a common conceptual content. There was also an open-ended question. From these questions 54 were assessed, which were grouped together and formed 6 subscales of family resilience, as Tucker Sixbey (2005) suggests. More specifically, the subscales are as follows: 1) Family Communication and Problem Solving: here, 27 questions of the data collection tool correspond to it. The result of the subscale is given with Cronbach's alpha coefficient 0,96, whereas the horizontal sum of the individual questions forms the subscale's final rating with a span from 27 to 108 units. 2) Utilizing Social and Economic Resources: It is formed by 8 questions. Its rating is calculated by summing the participants' answers and it varies from 8 to 32 units. The subscale's reliability has a Cronbach's alpha index of 0,85.3) Maintaining Positive Outlook: The questions composing the subscale are 6. The internal validity was calculated with the 0,86 Cronbach's alpha coefficient and in the same way the subscale's rating is calculated which varies from 6 to 24 units. 4) Family Connectedness: It is composed of 6 questions, among which the four ones in which the scale was reversed for conceptual reasons are also included. The sum of the score of all the questions that compose it, shapes the subscale's rating which it can also vary from 6 as minimal value to 24 as maximum value. Its reliability, measured with the Cronbach's alpha coefficient, was found to be of 0,70. 5) Family Spirituality: The subscale is composed of 4 questions. From the sum of the answers' score its rating varies from 4 to 16 units and the measurement of its internal validity gave a Cronbach's alpha coefficient of 0,88. 6) Ability to Make Meaning of Adversity: It is formed by 3 questions, its rating is calculated by summing the answers of the respondent parents and it varies from 8 to 32 units. The subscale's reliability has a Cronbach's alpha index of 0,74 .

Taking into consideration the exception of 12 questions, it must be noted that the rating for the measurement of the total family resilience results from the horizontal sum of the 6 subscales and may vary from 66 to 264 units. Both for the total family resilience assessment scale and its entire individual subscales, higher scores indicate higher levels of family resilience. The reliability and internal validity in total for the tool used were calculated with the Cronbach's alpha coefficient and was found to be of 0,96 . It is noted that the open-ended question was omitted.

Parenting Stress Index-Short Form: The parenting stress degree was measured by using the PSI-SF index (Abidin, 1995), which calculates the stress of the parents with children with autism spectrum disorders, which comes exclusively from their role as parents, without taking into consideration any external stressful factors, apart from the parent-child relation, as well as the child himself. The measurement tool consisted of 36 closed-type questions that were answered based on the 5-point Likert scale (1 to 5 = "I strongly disagree", "I disagree", "I am not sure", "I agree" and "I fully agree"). They were grouped together in three groups equal in number, that shaped the three index subscales as follows: 1) Parental Distress: It is made of questions 1-12 of the PSI-SF tool. The subscale rating is calculated by summing the answers and it varies from 12 to 60 units, reflecting the stress that is due to factors that concern the parents and which relate to the child's upbringing. The subscale's reliability has a Cronbach's alpha index of 0,85. 2) Parent-Child Dysfunctional Interaction: Questions 13 to 24 compose the second subscale of the Parenting Stress Index which represents the disappointment the parents feel regarding their interactions with their child. The sum of the score of all the questions that compose it, shapes its rating which may also vary from the minimum value of 12 units to the maximum value of 60 units. The subscale's reliability measured with the Cronbach's alpha coefficient was found to be of 0,68. 3) Difficulty of Child: It is formed by the twelve last questions in the questionnaire, 25 to 36. Its rating is calculated by summing the parents' answers, it varies from 12 to 60 units and assesses their perception about the self-regulation of their child's behavior. The subscale's reliability has a Cronbach's alpha index of 0,78 .

The rating for the measurement of the total Parenting Stress results from the horizontal sum of the 3 subscales and varies from 66 to 264 units. Both for the scale and its subscales, high scores indicate high stress levels, whereas a low rating indicates low stress levels. According to the PSI-SF self-report index, the values between the $15^{\text {th }}$ and $80^{\text {th }}$ percentage point of distribution are considered to be normal stress levels, whereas for the 
individuals whose rating varies from values above the $90^{\text {th }}$ percentage point of distribution, it is regarded that they are in the clinical range of high stress levels. The reliability and internal validity in total for the tool used was calculated with the Cronbach's alpha coefficient and was found to be of 0,84 .

The consistency check was performed via the alpha "coefficient" of Cronbach (Cronbach's a), with the use of which the reliability of the data collection tools and their individual parts is defined. Coefficient values higher than 0,6 are considered satisfactory and they ensure their cohesion and internal validity, functioning as elements of a unified group. For the description of the quantitative variables that participated in the statistical analysis, the mean values (Mean), the standard deviations (Standard Deviation $=\mathrm{SD}$ ), the minimal and maximum values (Min-Max) as well as the third and fourth order moments (Skewness and Kurtosis) of their distributions were used. In the case of the qualitative data, their description was made via the recording of their relevant absolute (n) and percent (\%f) frequencies. The linear correlation check between the quantitative variables was conducted via the Pearson $r$ correlation coefficient. The $r$ correlation coefficient varies between -1 and 1 , whereas the higher it is in absolute value, the higher the correlation between the variables becomes. Even though there are no commonly accepted limits, index values, to an absolute value, lower than 0,3 indicate weak correlations, values between 0,3 and 0,5 indicate medium correlations, whereas values higher than 0,5 mark high and strong correlations. Positive values of the coefficient suggest a positive correlation, whereas negative values, a negative correlation. The statistical significance of the correlations is checked at significance levels $\alpha=1 \%$ and $\alpha=5 \%$. For the comparison of the quantitative variables and the drawing of the survey's main conclusions, the Independent Samples t-test and the Paired Samples t-test were used depending on the nature and kind of the variables under examination. Moreover, its generalization for variables with more than two levels, the one-way Analysis of Variance (ANOVA), was used. The further study on the differences in the factors' levels is carried out with the Tukey method for multiple comparisons. The check of the hypothesis on equality of the variances on the factors' levels is performed via the Levene's test, whereas the safeguarding of the basic conditions concerning regularity and independence of the method's errors was checked via the Kolmogorov-Smirnov test and the Runs test, respectively. The aforementioned hypothesis checks are performed at a significance level $\alpha=5 \%$. For the processing and statistical analysis of the data the IBM SPSS Statistics 20 data statistic analysis software package was used.

\section{Results}

\subsection{Family Income}

The impact of factors, such as the economic soundness and the educational level, on the resilience of the parents of children with autism spectrum disorders was considered possible, thus there was the advisability for these parameters to be investigated. Initially, the impact of the economic soundness of the families with a child with autism spectrum disorders was investigated, at the levels of family resilience, social support and parenting stress of the parents. The results of the Analysis of Variance according to the factor of the annual family income for the measured scales and subscales, which emerged statistically significant at significance level $a=5 \%$, are shown in Table 1. There, the results of the Analysis of Variance per factor for those measured variables for which no statistically significant differentiations emerged, are included.

Table 4. Analysis of Variance of the measurement scales and subscales as to the respondents' annual family income

\begin{tabular}{|c|c|c|c|c|c|c|}
\hline Scales & Annual family income & Mean & SD & df & $\mathbf{F}$ & p-value \\
\hline \multirow{3}{*}{ SSI } & Below $15.000 €$ & 39,38 & 5,128 & \multirow{3}{*}{621} & \multirow{3}{*}{106,814} & \multirow{3}{*}{$0,000^{*}$} \\
\hline & $15.000-20.000 €$ & 43,65 & 3,472 & & & \\
\hline & Over $20.000 €$ & 45,83 & 3,189 & & & \\
\hline \multirow{3}{*}{ FRAS totally } & Below $15.000 €$ & 151,56 & 9,013 & & \multirow{3}{*}{43,869} & \multirow{3}{*}{$0,000^{*}$} \\
\hline & $15.000-20.000 €$ & 154,04 & 5,724 & \multirow{2}{*}{621} & & \\
\hline & Over $20.000 €$ & 160,56 & 9,043 & & & \\
\hline \multirow{2}{*}{ FCPS } & Below $15.000 €$ & 77,27 & 5,083 & 2 & \multirow{2}{*}{40,894} & \multirow{2}{*}{$0,000^{*}$} \\
\hline & $15.000-20.000 €$ & 78,86 & 3,199 & 621 & & \\
\hline
\end{tabular}




\begin{tabular}{|c|c|c|c|c|c|c|}
\hline & Over $20.000 €$ & 82,19 & 5,403 & & & \\
\hline \multirow{3}{*}{ USER } & Below $15.000 €$ & 22,27 & 1,755 & \multirow{3}{*}{$\begin{array}{c}2 \\
621\end{array}$} & \multirow{3}{*}{40,802} & \multirow{3}{*}{$0,000^{*}$} \\
\hline & $15.000-20.000 €$ & 22,75 & 1,157 & & & \\
\hline & Over $20.000 €$ & 23,92 & 1,146 & & & \\
\hline \multirow{3}{*}{ MPO } & Below $15.000 €$ & 17,04 & 1,281 & \multirow{3}{*}{$\begin{array}{c}2 \\
621\end{array}$} & \multirow{3}{*}{31,234} & \multirow{3}{*}{$0,000 *$} \\
\hline & $15.000-20.000 €$ & 17,42 & 0,901 & & & \\
\hline & Over $20.000 €$ & 18,12 & 1,142 & & & \\
\hline \multirow{3}{*}{ FS } & Below $15.000 €$ & 11,77 & 1,511 & \multirow{3}{*}{$\begin{array}{c}2 \\
621\end{array}$} & \multirow{3}{*}{9,664} & \multirow{3}{*}{$0,000^{*}$} \\
\hline & $15.000-20.000 €$ & 11,39 & 1,518 & & & \\
\hline & Over $20.000 €$ & 12,13 & 1,493 & & & \\
\hline \multirow{3}{*}{ AMMA } & Below $15.000 €$ & 8,30 & 1,095 & \multirow{3}{*}{$\begin{array}{c}2 \\
621\end{array}$} & \multirow{3}{*}{29,878} & \multirow{3}{*}{$0,000^{*}$} \\
\hline & $15.000-20.000 €$ & 8,66 & 0,685 & & & \\
\hline & Over $20.000 €$ & 9,13 & 0,865 & & & \\
\hline \multirow{3}{*}{ PSI-SF totally } & Below $15.000 €$ & 120,06 & 12,994 & \multirow{3}{*}{$\begin{array}{c}2 \\
621\end{array}$} & \multirow{3}{*}{53,242} & \multirow{3}{*}{$0,000^{*}$} \\
\hline & $15.000-20.000 €$ & 115,18 & 13,806 & & & \\
\hline & Over $20.000 €$ & 101,97 & 18,094 & & & \\
\hline \multirow{3}{*}{ PD } & Below $15.000 €$ & 38,97 & 4,847 & \multirow{3}{*}{$\begin{array}{c}2 \\
621\end{array}$} & \multirow{3}{*}{62,753} & \multirow{3}{*}{$0,000^{*}$} \\
\hline & $15.000-20.000 €$ & 36,71 & 4,824 & & & \\
\hline & Over $20.000 €$ & 31,87 & 6,735 & & & \\
\hline \multirow{3}{*}{ P-CDI } & Below $15.000 €$ & 41,65 & 4,952 & \multirow{3}{*}{$\begin{array}{c}2 \\
621\end{array}$} & \multirow{3}{*}{29,314} & \multirow{3}{*}{$0,000^{*}$} \\
\hline & $15.000-20.000 €$ & 40,74 & 4,829 & & & \\
\hline & Over $20.000 €$ & 36,79 & 6,497 & & & \\
\hline \multirow{3}{*}{ DC } & Below $15.000 €$ & 39,44 & 5,722 & \multirow{3}{*}{$\begin{array}{c}2 \\
621\end{array}$} & \multirow{3}{*}{34,734} & \multirow{3}{*}{$0,000^{*}$} \\
\hline & $15.000-20.000 €$ & 37,73 & 5,919 & & & \\
\hline & Over $20.000 €$ & 33,30 & 6,639 & & & \\
\hline
\end{tabular}

\section{Memo}

SSI: $\quad$ Social Support Index

FRAS: $\quad$ Family Resilience Assessment Scale

FCPS: $\quad$ Family Communication and Problem Solving

USER: Utilizing Social and Economic Resources

MPO: $\quad$ Maintaining Positive Outlook

FC: $\quad$ Family Connectedness

FS: $\quad$ Family Spirituality

AMMA: $\quad$ Ability to Make Meaning of Adversity

PSI-SF: $\quad$ Parenting Stress Index - Short Form

PD: $\quad$ Parental Distress

P-CDI: $\quad$ Parent-Child Dysfunctional Interaction

DC: $\quad$ Difficulty of Child 
It is found (Table 4 ) that higher levels of family income are connected to higher levels of total family resilience FRAS $(F(2,620)=43,869, p=0,000)$, higher levels of social support SSI $(F(2,620)=106,814, p=0,000)$ and lower levels of parenting stress $(F(2,620)=53,242, p=0,000)$. Tukey's multiple comparison method diffuses these differentiations to all the levels of the factor, separating each level of it from the rest. More analytically, for the total FRAS scale, the average rating of parents with annual income below15,000 $€$ amounts to $M=151,56$, for parents with income between $15,000 €$ and $20,000 €$ to $M=154,04$ and for parents with annual income over $20,000 €$ to $M=160,56$. The respective average ratings per income for the SSI social support scale are $M=39,38, M=43,65$ and $M=45,83$, while for the total stress index they are formed as $M=120,06$, $M=115,18$ and $M=101,97$.

The results of the check for all the subscales of family resilience are the same, apart from the subscale which concerns family connectedness (FC), the high levels of the annual family income being connected to their high average rating. The value of the statistical function used for FCPS subscale was found to be $F(2,620)=40,894$ with $p=0,000$, for USER subscale $E(2,620)=40,802$ with $p=0,000$, MPO $F(2,620)=31,234$ with $p=0,000$, for FS component it is $F(2,620)=9,664$ with $p=0,000$ and for AMMA $E(2,620)=29,878$ with $=0,000$. Tukey's multiple comparison method, as in the case of the total scale, diffuses these differentiations among all the levels of the factor for all the subscales except for family connectedness (FS), for which only the middle incomes are separated from the rest and which show the lowest average rating in the subscale. The value of the average rating per annual family income for each one of the above components is shown, as it has already been mentioned, in Table 4.

Exactly the same image is also crystallized for the individual components of parenting stress. At significance level $\mathrm{a}=\mathbf{5 \%}$, the differences among the levels of annual family income, emerge statistically significant, both for the values of PD subscale $(F(2,620)=62,753, p=0,000)$ and for those of the P-CDI $(F(2,620)=29,314, p=0,600)$ and DC $(F(2,620)=34,734, p=0,000)$ scales. The higher the annual family income is for the parents with a child with autism spectrum disorders, the lower their average rating is in PD and DC subscales, all the levels of the factor being separated among them. On the contrary, the multiple comparison method at the levels of annual family income for P-CDI subscale, separates only the highest of them from the rest, without the lower and middle ones being differentiated among them.

\subsection{Educational Level}

The statistical processing of the sample's data revealed, at a significance level $a=0,05$, statistically significant differences in the values of the measured characteristics in comparison with the higher educational level of the parents with a child with autism spectrum disorders. Table 5 shows the results of the analysis of variance per factor for each one of the variables examined. As a general rule, the higher educational level of the parents is connected to higher levels of family resilience, higher levels of social support and lower levels of parenting stress.

Table 5. Analysis of Variance of the measurement scales and subscales as to the respondents' higher level of education

\begin{tabular}{|c|c|c|c|c|c|c|}
\hline Scales & Higher education level & Mean & SD & df & $\mathbf{F}$ & p-value \\
\hline \multirow{4}{*}{ SSI } & of Primary Education & 37,94 & 5,023 & & \multirow{4}{*}{116,174} & \multirow{4}{*}{$0,000 *$} \\
\hline & Secondary School Graduates & 40,58 & 4,641 & 3 & & \\
\hline & Lyceum Graduates & 43,40 & 3,316 & \multirow[t]{2}{*}{620} & & \\
\hline & HEI/TEI Graduates & 45,18 & 2,905 & & & \\
\hline \multirow{4}{*}{ FRAS totally } & of Primary Education & 152,09 & 10,841 & & \multirow{4}{*}{8,801} & \multirow{4}{*}{$0,000^{*}$} \\
\hline & Secondary School Graduates & 151,74 & 6,062 & 3 & & \\
\hline & Lyceum Graduates & 154,30 & 5,284 & 620 & & \\
\hline & HEI/TEI Graduates & 155,85 & 8,089 & & & \\
\hline \multirow{3}{*}{ FCPS } & of Primary Education & 77,50 & 6,154 & \multirow{3}{*}{$\begin{array}{c}3 \\
620\end{array}$} & \multirow{3}{*}{9,768} & \multirow{3}{*}{$0,000 *$} \\
\hline & Secondary School Graduates & 77,55 & 3,367 & & & \\
\hline & Lyceum Graduates & 78,88 & 2,973 & & & \\
\hline
\end{tabular}




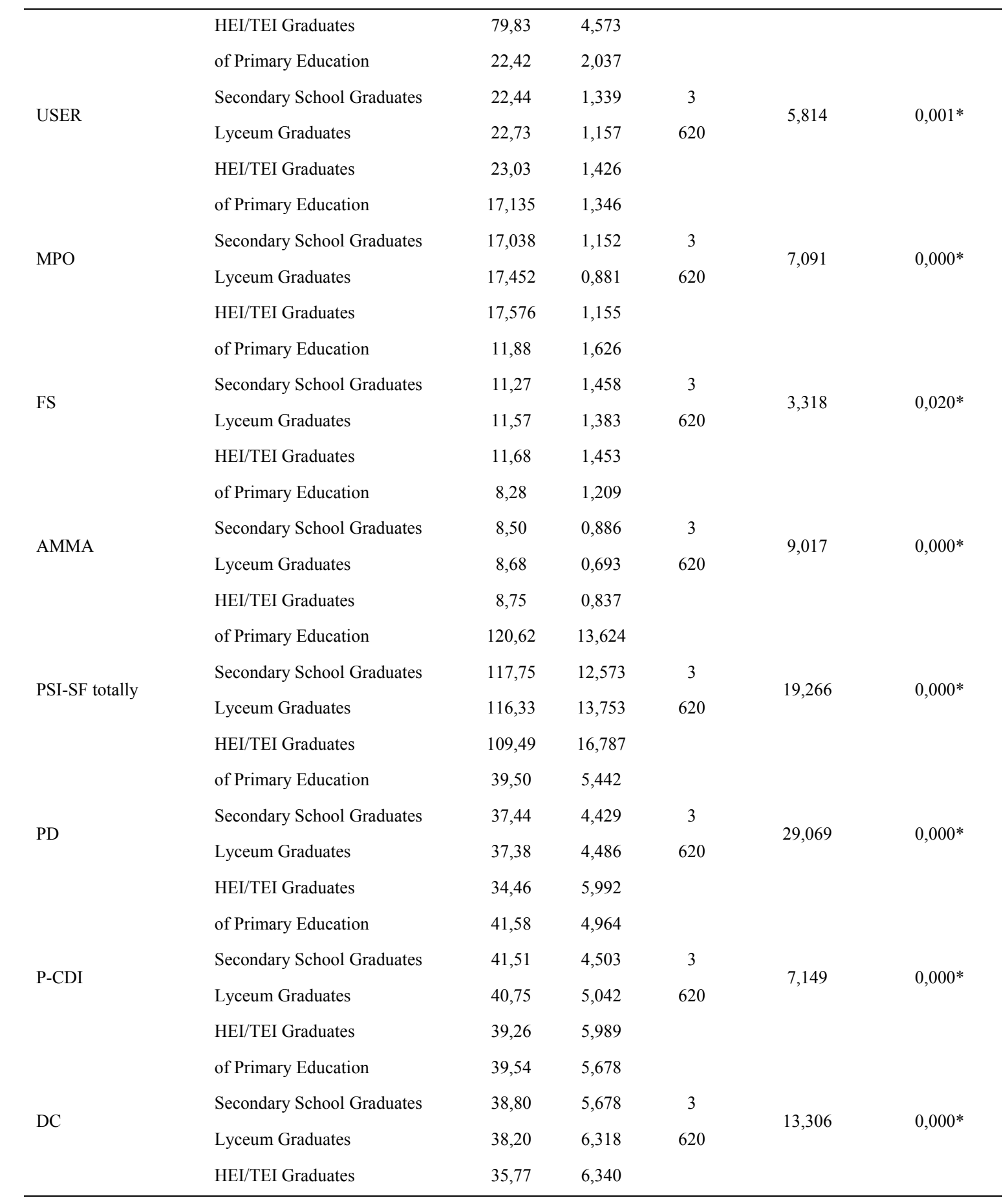

Note. $*=\mathrm{p}<.05$.

(Memo: the memo of table. 4 applies)

More specifically, higher educational levels are connected to high values in the total scale of social support SSI $(F(3,620)=116,174, p=0,000)$, the multiple comparisons with the Tukey method, at the levels of the factor, diffusing this differentiation among all of the factor. Regarding the total scale of family resilience FRAS, high educational levels are also connected to high values of the scale $(F(3,620)=8,801, p=0,000)$, the multiple comparisons separating the Higher Education Institute (HEI)/Technical Educational Institute (TEI) graduates from the parents of primary education and secondary school graduates. 
Regarding FCPS subscale, the multiple comparison method revealed differentiations among the parents who have completed their primary education and the graduates of Lyceum and Higher Education Institute (HEI)/Technical Educational Institute (TEI), the first ones showing lower average rating. Moreover, secondary school (Gymnasium) graduates show statistically significantly, a lower average score in the subscale in comparison with Higher Education Institute (HEI)/Technical Educational Institute (TEI) graduates, while the remaining combinations of the levels are not differentiated statistically significantly at significance level $a=5 \%$. The value of the statistical function for the control of the cases was found to be $F(3,620)=9,768$ with $p=0,000$. Higher Education Institute (HEI)/Technical Educational Institute (TEI) graduates present a higher average score in the USER subscale of family resilience in comparison with the parents with levels of primary education and secondary school graduates $(F(3,620)=5,814, p=0,001)$, the multiple comparisons not showing the differentiations among the remaining levels of the factor to be statistically significant. The average rating of MPO subscale appears statistically significantly higher for the university graduate parents in comparison with the ones of primary education and secondary school graduates, as well as Lyceum graduates with Secondary School graduates $(F(3,620)=7,091, p=0,000)$, while the same method produced a lower average score for the parents of primary education against the Secondary school graduates in FS component $(F(3,620)=3,318, p=0,020)$. For AMMA subscale, the differences in the average rating of the parents of primary education with the Lyceum graduates and the Higher Education Institute (HEI)/Technical Educational Institute (TEI) degree holders were found statistically significant, the two last groups showing a higher average score in the subscale $(F(3,620)=9,017, p=0,000)$.

\section{Discussion}

The annual family income has a significant impact on the formation of the studied characteristics. The higher the economic soundness of the parents with a child with autism spectrum disorders, the higher the social support they have, the higher the resilience which they develop and the milder the feeling of stress which they experience. The same general conclusion also concerns the individual dimensions of the family resilience apart from the family connectedness, which is not related significantly to the annual family income, but also for all the individual aspects of parenting stress.

As in the case of the educational level, likewise for the family income, while no special emphasis was put in the theoretical part, occasional references highlighted its importance and the findings of this research are in accordance with the significance of the role it plays. It should be noted that the availability of a good income does not necessarily ensure the parents' resilience, because their stress is often due to their weakness to utilize the resources they have in the right way in order to effectively help their child (Batool \& Khurshid, 2015). This is an issue of autism management in general. More specifically, the good family income was expected to help combating the stress of the parents, since the economic requirements of the treatment are often major and therefore stressful (Bashir et al., 2014). Moreover, Bhagat, Simbak and Haque (2015) observe that autism is a serious, persistent and dynamic disease, which is often also aggravated by the behavior of the parents towards their children, because they face, among other things, economic problems. Actually, each therapeutic intervention, which also concerns the behavior of the parents towards the problem, should take the economic issues into serious consideration.

The parents' educational level is also significantly related to the social support the parents of the child with autism receive. The higher the parents' higher educational level, the greater the social support they have. The same general principle also governs the relation of the educational level to the parents' resilience as a whole, as well as its different aspects except for the family connectedness, without this being diffused evenly and being differentiated for all the educational levels. On the other hand, its impact is reverse on the formation of the levels of the total stress, the parental distress, the parent-child dysfunctional interaction and child difficulty, lower educational levels being connected to the higher levels of the aforementioned characteristics.

In the theoretical part, the parents' educational level was occasionally discussed, without, however, putting very strong emphasis on this parameter. Here, the conclusion of Samadi and McConkey (2014) that the parents' lower educational level is connected to their less good health, may be retracted, as well as that the greater awareness on autism outweighs the cultural differentiations that might be present in the way the parents take care of their autistic children. Increased awareness may be beneficial because the better informing on the child's management in the house will, potentially, also bring about the support of the extended family and friends. Moreover, Yang et al. (2016) find that the emotional symptoms of autism are significantly related to the parents' educational level, the stress they experience, as well as the characteristics of their personality, such as neuroticism and psychoticism. 
Therefore, in this research, too, the parents' education emerges as a determining factor for the parents' wellbeing and for autism management. Furthermore, it should be mentioned that Ammari, Ringel Morris and Yardi Schoenebeck (2016) find the ever-increasing search for information on autism on the internet, to which the parents resort, who, certainly, should be in a position of distinguishing the reliable information from the falsehoods. They should also be in a position of avoiding the downgrading of their personal experiences to general stereotypes and of resisting negative criticism and stigmatization that are scattered over the Internet. Selimoglu et al. (2013) also found that the parents of autistic children in their sample turn to the internet for information about autism, at a smaller percentage though. And many attempt to get the necessary information through reading books on autism. Therefore, the educational level plays an important role, and this is one conclusion of our research, which connects the social support to the parents and the enhancement of their resilience to the education they have received in the past.

\section{Methodological Limitations}

The geographical distribution of the sample can be regarded as one basic limitation of the research. Despite the fact that as to its size, it is big enough and representative per district, it concerns only seven prefectures in the Greek territory. Consequently, generalizations of the conclusions that are drawn will have to be made with caution, even though it seems that they can be considered as particularly representative. An equally important limitation is that fact that the sample taken is exclusively from parents of a specific family structure. The families chosen are all two-parent families and the parents who participate in the survey have a specific family relation to the child. So, it cannot be assumed that the effects of the family structure and family relation have been adequately explored. Besides, the assessment that was made is based on the self-reports of the parents with a child with autism spectrum disorders, without other reports and information from other important persons of the parents' environment being detected, such as the rest of the families' members and health experts who possibly aid the parents. It must also be added that the survey is synchronic and interrelated, therefore it is not possible to discuss casual links between the factors under study. In addition, in this attempt no other possible parameters and co-morbidities linked to the levels of family resilience were assessed, such as depression, loneliness, the parents' interpersonal relations and social skills. All the aforementioned limitations must be taken into consideration during the study and interpretation of the present research findings.

\section{Conclusions}

The research highlighted a significant impact of the annual family income on the formation of the levels of the studied characteristics, as the conclusion was drawn that the level of the economic soundness is positively linked to the social support the parents receive and the resilience they develop. On the contrary, the stress they feel is reduced. The image of the individual dimensions of the family resilience is similar, however, the family connectedness, which the family income does not affect significantly, is excluded. Similarly, the educational level is connected to the social support. The former increases when the latter increases, and the same principle also determines the relation of parents' educational level and resilience, both as a whole, and in its different aspects, except for the family connectedness, without, however, this being differentiated for all the educational levels. On the contrary, the educational level affects reversely the levels of total stress, the parental distress, the parent-child dysfunctional interaction and child difficulty. A lower educational level increases their values.

\section{References}

Abidin, R. R. (1995). Parenting Stress Index (3rd ed.). Odessa, FL: Psychological Assessment Resource.

Ammari, T., Ringel Morris, M., \& Yardi Schoenebeck, S. (2014). Accessing Social Support and Overcoming Judgment on Social Media among Parents of Children with Special Needs. In AAAI International Conference on Weblogs and Social Media 2014 (ICWSM 14). Ann Arbor, MI. Retrieved December 3, 2014, from http://research.microsoft.com/pubs/210198/ammari_ICWSM2014.pdf

Bashir, A., Bashir, U., Lone, A., \& Ahmad, Z. (2014). Challenges faced by families of autistic children. International Journal of Interdisciplinary Research and Innovations, 2(1), 64-68.

Batool, S. S., \& Khurshid, S. (2015). Factors associated with Stress among Parents of Children with Autism. Journal of the College of Physicians and Surgeons Pakistan, 25(10), 752-756.

Bhagat, V., Simbak, N. B., \& Haque, M. (2015). The Peripheral Focus on the Psychological Parameters of Parents of Autistic Children in the Intervention Methods: A Review and Recommending the Strategy, Focusing Psychological Parameters of Parents of Autistic Children in Intervention Methods. Journal of Young Pharmacists, 7(4) (Supple), 403-413. https://doi.org/10.5530/jyp.2015.4s.1 
Fischer, J., Corcoran, K., \& Fischer, J. (2007). Measures for clinical practice and research: A sourcebook. New York: Oxford University Press.

Houser, R., \& Seligman, M. (1991). A comparison of stress and coping by fathers of adolescents with mental retardation and fathers of adolescents without mental retardation. Research in Developmental Disabilities, 12, 251-260. https://doi.org/10.1016/0891-4222(91)90011-G

Keller, D., \& Honig, A. S. (2004). Maternal and Paternal Stress in Families with School-Aged Children with $\begin{array}{lllll}\text { Disabilities. American Journal of } & \text { Orthopsychiatry, }\end{array}$ https://doi.org/10.1037/0002-9432.74.3.337

McCubbin, H. I., Patterson, J., \& Glynn, T. (1982). Social Support Index (SSI). In H. I. McCubbin, A. I. Thompson, \& M. A. McCubbin (Eds.), Family assessment: Resiliency, coping and adaptation-Inventories for research and practice (pp. 357-389). Madison, WI: University of Wisconsin System.

Samadi, S. A., \& McConkey, R. (2014). The impact on Iranian mothers and fathers who have children with an autism spectrum disorder. Journal of Intellectual Disability Research, 58(3), 243-254. https://doi.org/10.1111/jir.12005

Selimoglu, O. G., Ozdemir, S., Toret, G., \& Ozkubat, U. (2013). An Examination of the Views of Parents of Children with Autism About Their Experiences at the Post-Diagnosis Period of Autism. International Journal of Early Childhood Special Education, 5(2), 162-167.

Tucker Sixbey, M. (2005). Development of the Family Resistance Assessment Scale to Identify Family Resilience Constructs. University of Florida. Retrieved December 3, 2014, from http://etd.fcla.edu/UF/UFE0012882/sixbey_m.pdf

Walsh, F. (2006). Strengthening family resilience (2nd ed.). New York: Guilford Press.

Yang, C.-H., Du, Y.-S., Gong, Y., Liu, W.-W., \& Kutcher, S. (2016). Depressive symptoms and their correlates in parents of children with autism spectrum disorders. Int J Clin Exp Med, 9(2), 5135-5143.

\section{Copyrights}

Copyright for this article is retained by the author(s), with first publication rights granted to the journal.

This is an open-access article distributed under the terms and conditions of the Creative Commons Attribution license (http://creativecommons.org/licenses/by/4.0/). 